Supporting Information

\title{
Development of the Ca - Au - In Icosahedral Quasicrystal and Two Crystalline Approximants: Practice via Pseudogap Electronic Tuning
}

Qisheng Lin, John D. Corbett ${ }^{*}$

Department of Chemistry, Iowa State University, Ames, IA, 50010

Table S1. Anisotropic displacement parameters $\left(\AA^{2} \mathrm{x} 10^{3}\right)$ for $\mathrm{Ca}_{3} \mathrm{Au}_{12.4(1)} \operatorname{In}_{6.1(1)} 1 / 1 \mathrm{AC}$. The anisotropic displacement factor exponent takes the form: $-2 \pi^{2}\left[h^{2} a^{* 2} U^{11}+\ldots+2\right.$ $\mathrm{hka}^{*} \mathrm{~b}^{*} \mathrm{U}^{12}$ ]

\begin{tabular}{|l|l|l|l|l|l|l|}
\hline & $\mathrm{U}^{11}$ & $\mathrm{U}^{22}$ & $\mathrm{U}^{33}$ & $\mathrm{U}^{23}$ & $\mathrm{U}^{13}$ & $\mathrm{U}$ \\
\hline $\mathrm{Au} 1$ & $34(1)$ & $18(1)$ & $15(1)$ & $-2(1)$ & 0 & 0 \\
\hline $\mathrm{Au} / \mathrm{In} 2$ & $53(1)$ & $22(1)$ & $31(1)$ & $-5(1)$ & $16(1)$ & $-8(1)$ \\
\hline $\mathrm{In} 3$ & $15(1)$ & $40(2)$ & $13(1)$ & 0 & 0 & 0 \\
\hline $\mathrm{Au} / \mathrm{In} 4$ & $33(1)$ & $33(1)$ & $33(1)$ & $13(1)$ & $13(1)$ & $13(1)$ \\
\hline $\mathrm{Au} / \mathrm{In} 5$ & $29(1)$ & $30(2)$ & $18(1)$ & $2(1)$ & 0 & 0 \\
\hline $\mathrm{Au} / \mathrm{In} 6$ & $24(1)$ & $19(1)$ & $51(2)$ & 0 & 0 & 0 \\
\hline $\mathrm{In} 7$ & $66(6)$ & $30(4)$ & $73(7)$ & $3(4)$ & 0 & 0 \\
\hline $\mathrm{In} 8$ & $66(5)$ & $66(5)$ & $66(5)$ & $13(4)$ & $13(4)$ & $13(4)$ \\
\hline $\mathrm{Ca}$ & $21(3)$ & $49(4)$ & $13(3)$ & 0 & $-2(2)$ & 0 \\
\hline
\end{tabular}


Table S2. Anisotropic displacement parameters $\left(\AA^{2} \times 10^{3}\right)$ for $\mathrm{Ca}_{12.6(1)} \mathrm{Au}_{37.0(2)} \operatorname{In}_{39.6(6)} 2 / 1$ AC. The anisotropic displacement factor exponent takes the form: $-2 \pi^{2}\left[\mathrm{~h}^{2} \mathrm{a}^{* 2} \mathrm{U}^{11}+\ldots+2\right.$ $\left.h k a{ }^{*}{ }^{*} U^{12}\right]$

\begin{tabular}{|l|l|l|l|l|l|l|}
\hline & $\mathrm{U}^{11}$ & $\mathrm{U}^{22}$ & $\mathrm{U}^{33}$ & $\mathrm{U}^{23}$ & $\mathrm{U}^{13}$ & $\mathrm{U}^{12}$ \\
\hline $\mathrm{Au} 1$ & $11(1)$ & $19(1)$ & $17(1)$ & $3(1)$ & $0(1)$ & $5(1)$ \\
\hline $\mathrm{Au} 2$ & $15(1)$ & $15(1)$ & $20(1)$ & $0(1)$ & $2(1)$ & $-4(1)$ \\
\hline $\mathrm{Au} 3$ & $25(1)$ & $13(1)$ & $21(1)$ & $-6(1)$ & $1(1)$ & $-3(1)$ \\
\hline $\mathrm{Au} / \mathrm{In} 4$ & $16(1)$ & $17(1)$ & $13(1)$ & $-1(1)$ & $0(1)$ & $1(1)$ \\
\hline $\mathrm{Au} 5$ & $20(1)$ & $22(1)$ & $14(1)$ & $-1(1)$ & $-3(1)$ & $3(1)$ \\
\hline $\mathrm{Au} 6$ & $11(1)$ & $16(1)$ & $15(1)$ & $0(1)$ & $1(1)$ & $-1(1)$ \\
\hline $\mathrm{Au} 7$ & $13(1)$ & $13(1)$ & $13(1)$ & $-2(1)$ & $-2(1)$ & $-2(1)$ \\
\hline $\mathrm{Au} 8$ & $16(1)$ & $12(1)$ & $16(1)$ & $-1(1)$ & $3(1)$ & $-1(1)$ \\
\hline $\mathrm{Au} 9$ & $15(1)$ & $11(1)$ & $12(1)$ & $-1(1)$ & $1(1)$ & $-1(1)$ \\
\hline $\mathrm{Au} / \mathrm{In} 10$ & $16(1)$ & $11(1)$ & $15(1)$ & $1(1)$ & $-1(1)$ & $1(1)$ \\
\hline $\mathrm{Au} 11$ & $12(1)$ & $17(1)$ & $16(1)$ & $0(1)$ & $0(1)$ & $3(1)$ \\
\hline $\mathrm{Au} / \mathrm{In} 12$ & $10(1)$ & $22(1)$ & $20(1)$ & $-9(1)$ & $-4(1)$ & $5(1)$ \\
\hline $\mathrm{Au} / \mathrm{In} 13$ & $18(1)$ & $19(1)$ & $18(1)$ & $1(1)$ & $4(1)$ & $2(1)$ \\
\hline $\mathrm{Au} / \mathrm{In} 14$ & $24(1)$ & $26(1)$ & $19(1)$ & $9(1)$ & $6(1)$ & $1(1)$ \\
\hline $\mathrm{Au} / \mathrm{In} 15$ & $24(1)$ & $21(1)$ & $29(1)$ & $-7(1)$ & $2(1)$ & $-6(1)$ \\
\hline $\mathrm{In} 16$ & $11(1)$ & $11(1)$ & $11(1)$ & $1(1)$ & $1(1)$ & $1(1)$ \\
\hline $\mathrm{Au} / \mathrm{In} 17$ & $35(1)$ & $18(1)$ & $27(1)$ & $-3(1)$ & $3(1)$ & $0(1)$ \\
\hline $\mathrm{In} 18$ & $47(1)$ & $10(1)$ & $11(1)$ & $-2(1)$ & $11(1)$ & $-8(1)$ \\
\hline $\mathrm{In} 19$ & $12(1)$ & $15(1)$ & $46(1)$ & $-14(1)$ & $-7(1)$ & $3(1)$ \\
\hline $\mathrm{In} 20$ & $42(1)$ & $17(1)$ & $12(1)$ & $-10(1)$ & $-13(1)$ & $17(1)$ \\
\hline $\mathrm{In} 21$ & $17(1)$ & $17(1)$ & $16(1)$ & $-3(1)$ & $-1(1)$ & $4(1)$ \\
\hline $\mathrm{In} 22$ & $14(1)$ & $31(1)$ & $16(1)$ & $-5(1)$ & $3(1)$ & $-9(1)$ \\
\hline & & & & & & \\
\hline
\end{tabular}




\begin{tabular}{|l|l|l|l|l|l|l|}
\hline In23a & $8(2)$ & $9(1)$ & $21(5)$ & $7(2)$ & $-4(2)$ & $-2(1)$ \\
\hline In23b & $22(17)$ & $9(4)$ & $22(5)$ & $4(4)$ & $-15(8)$ & $0(6)$ \\
\hline In24 & $14(1)$ & $14(1)$ & $16(1)$ & $4(1)$ & $-4(1)$ & $-3(1)$ \\
\hline In25 & $10(1)$ & $18(1)$ & $49(1)$ & $14(1)$ & $0(1)$ & $-1(1)$ \\
\hline In26 & $38(1)$ & $10(1)$ & $9(1)$ & $0(1)$ & $3(1)$ & $-7(1)$ \\
\hline In27 & $9(3)$ & $19(3)$ & $28(3)$ & $16(2)$ & $5(2)$ & $-2(2)$ \\
\hline In28 & $11(3)$ & $11(3)$ & $11(3)$ & $7(3)$ & $7(3)$ & $7(3)$ \\
\hline In29 & $23(3)$ & $23(3)$ & $23(3)$ & $-10(3)$ & $-10(3)$ & $-10(3)$ \\
\hline In30 & $80(5)$ & $80(5)$ & $80(5)$ & $62(5)$ & $62(5)$ & $62(5)$ \\
\hline Ca1 & $16(2)$ & $15(2)$ & $11(2)$ & $-4(2)$ & $3(2)$ & $0(2)$ \\
\hline Ca2 & $8(2)$ & $17(2)$ & $19(3)$ & $-6(2)$ & $-3(2)$ & $2(2)$ \\
\hline Ca3 & $12(2)$ & $8(2)$ & $11(2)$ & $1(2)$ & $-7(2)$ & $2(2)$ \\
\hline Ca4 & $9(2)$ & $13(2)$ & $8(2)$ & $1(2)$ & $-1(2)$ & $0(2)$ \\
\hline Ca5 & $19(3)$ & $19(3)$ & $19(3)$ & $18(3)$ & $18(3)$ & $18(3)$ \\
\hline
\end{tabular}




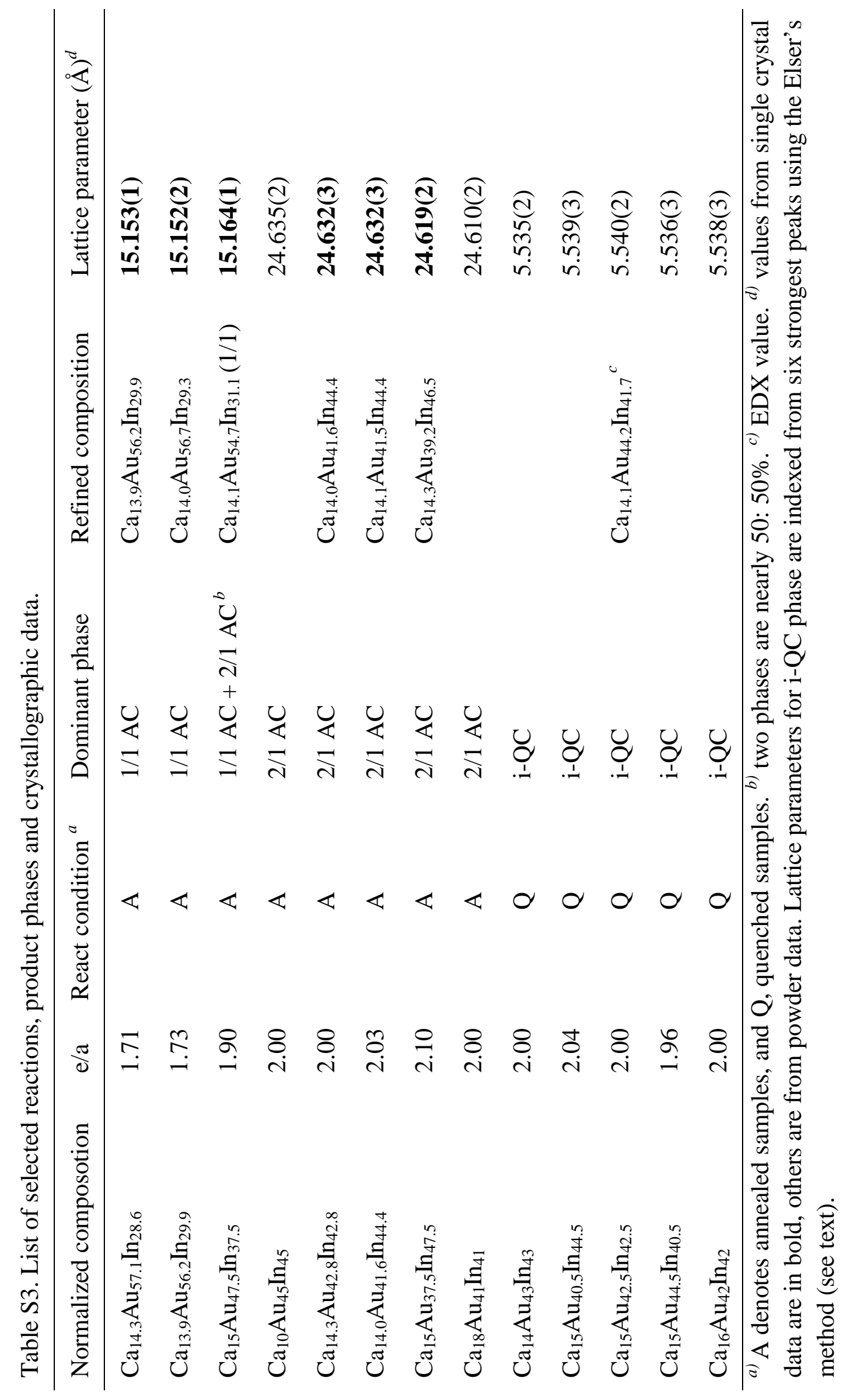




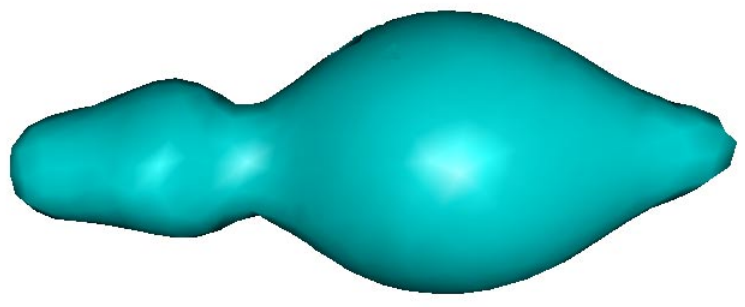

(a)

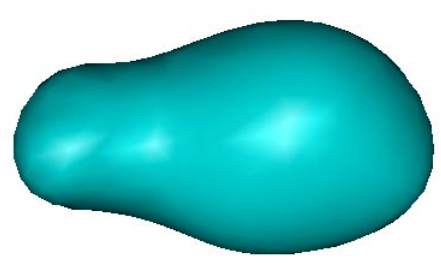

(c)

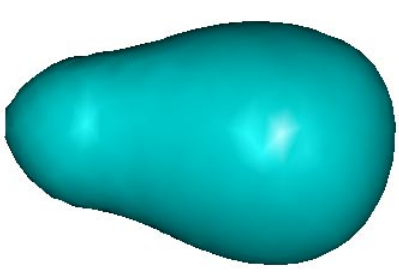

(b)

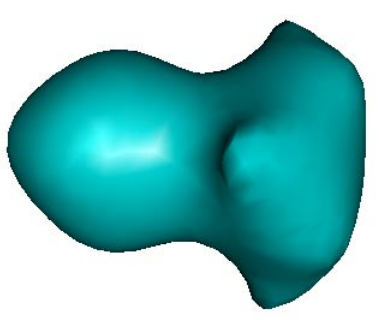

(d)

Fig. S1. Perspective view of observed electron densities for (a) Au/In4 and (b) Au/In5 in 1/1 AC, (c) In23 and (d) In28/In29 in 2/1 AC, showing the evidently split positions for each. Electron densities are drawn at $9 \mathrm{e} / \AA^{3}$ contour level. 

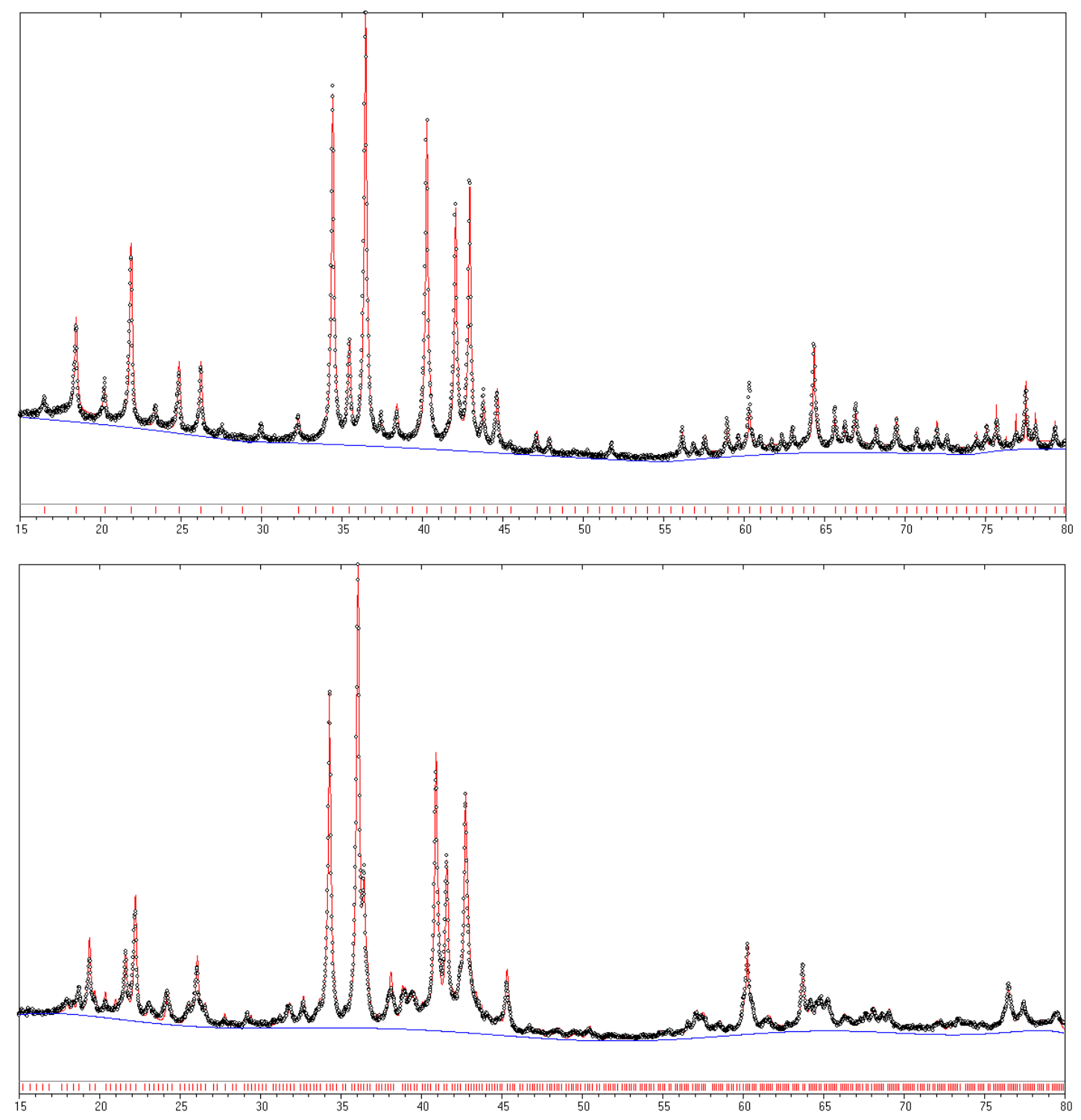

Fig. S2. Overlay of experimental (black circle) and calculated (red line) powder patterns for 1/1 (top) and 2/1 ACs (bottom). The backgrounds are shown (blue line) so that diffuse scattering can be seen. The net patterns are actually the same as shown in Fig. 2c. 


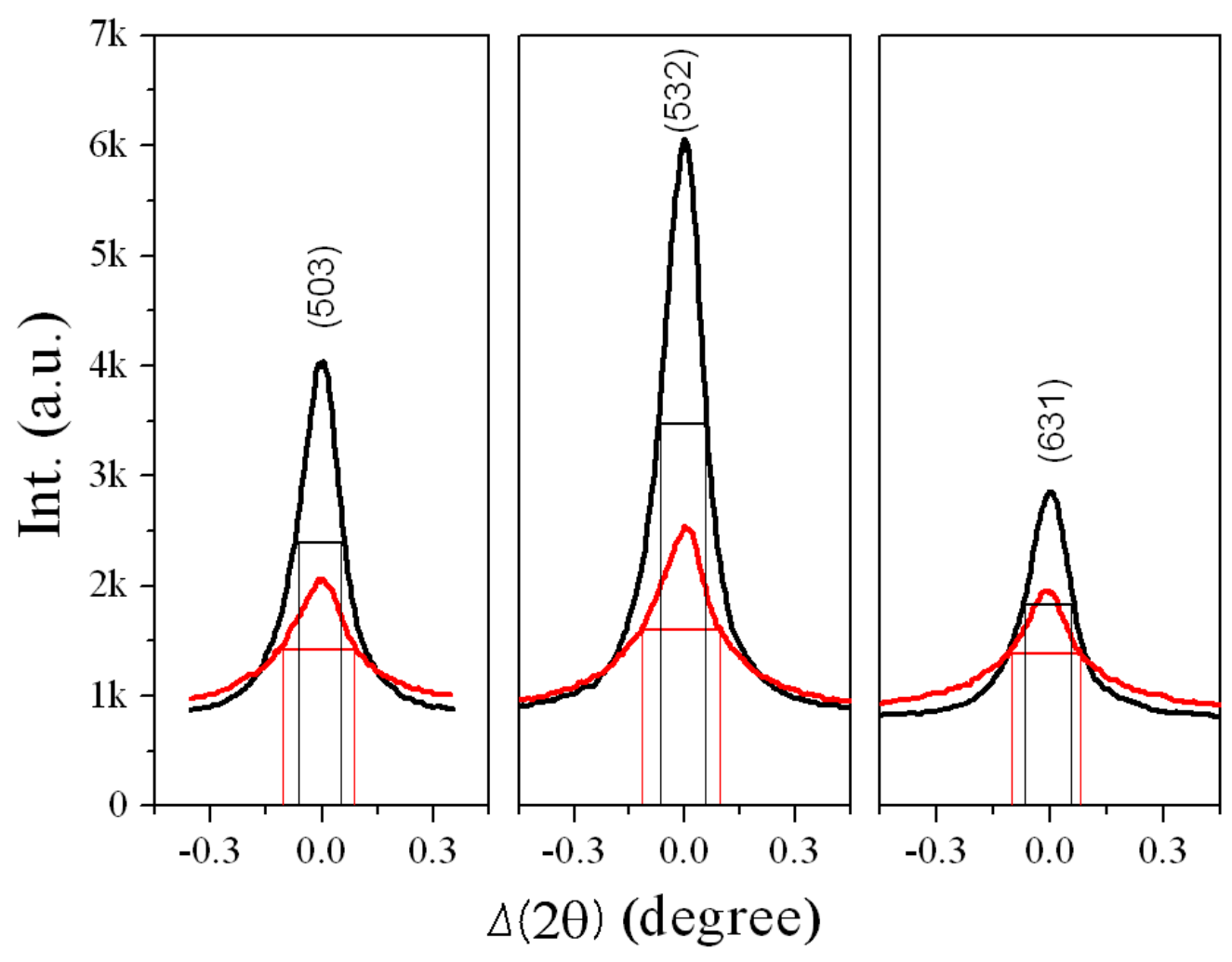

Fig. S3. Comparison of three strongest reflection peaks for the Tsai-type $\mathrm{Ca}-\mathrm{Au}-\mathrm{In}$ (red) and $\mathrm{Sc}-\mathrm{Mg}-\mathrm{Cu}-\mathrm{Ga}$ (black) 1/1 ACs, showing the relative larger peak widths (FWHM) and low intensities for the former; also see Fig. 2 and 3. For convenience, peak centers were shifted to same position so that intensities and peak widths could be compared. Intensity data were collected at same exposure time on the Guinier G670 powder diffractometer (text); sample volumes were guided by eye. 


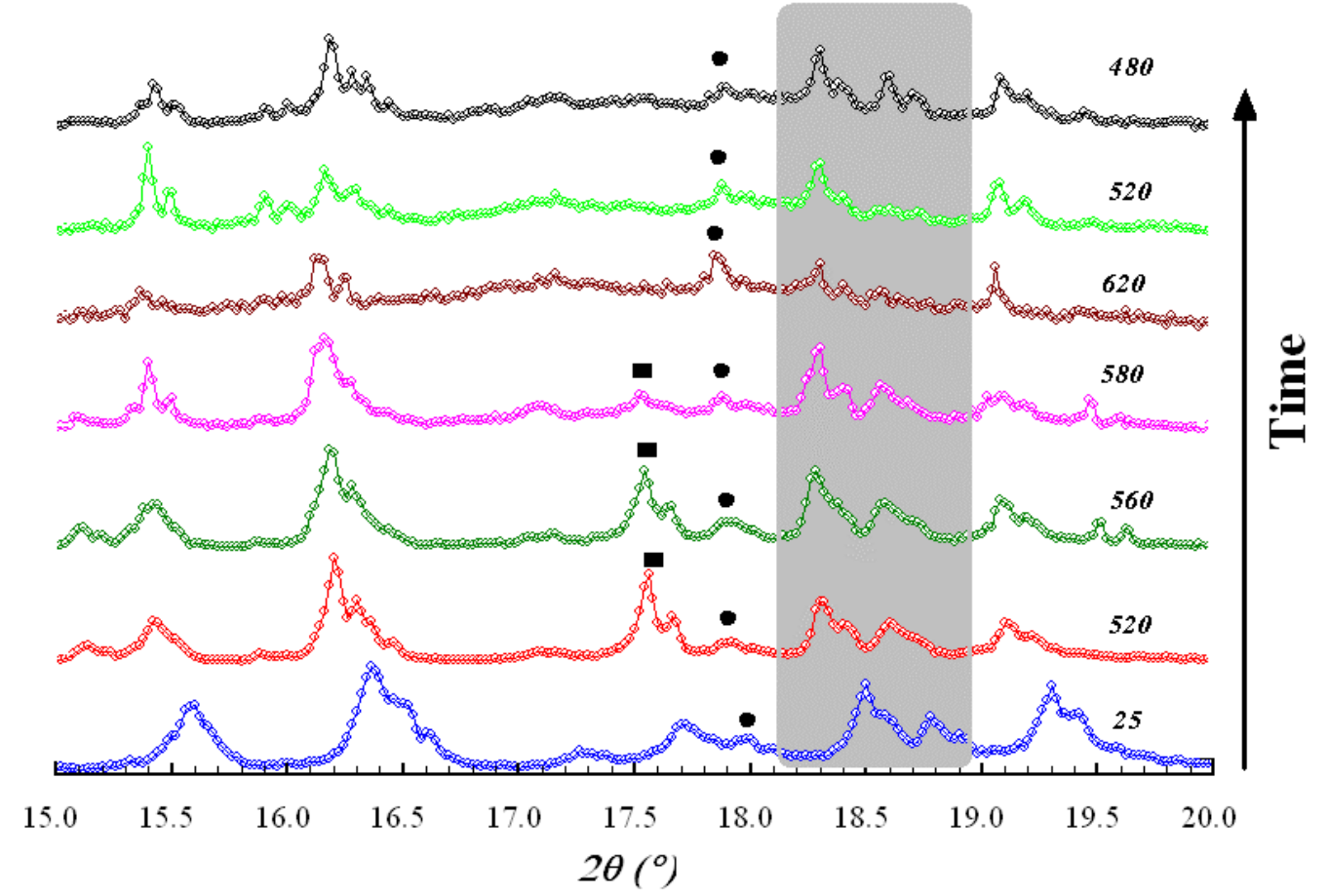

Fig. S4. Selected temperature-dependent X-ray powder pattern data (Mo $\mathrm{K} a$ ) for $\mathrm{Ca}_{12.6(1)} \mathrm{Au}_{37.0(2)} \mathrm{In}_{39.6(6)}$ 2/1 AC. No other phase transition is observed when sample is heated to and cooled from melting point, as guided by the shaded region. Numbers mark temperatures $\left({ }^{\circ} \mathrm{C}\right)$ at which patterns are recorded; solid squares denote the reflection peaks from AuIn 2 impurity, and, solid circles, from the Pt sample holder. 